\title{
Child Neurology: Recurrent Brainstem Strokes and Aphthous Ulcers in a Child With Mutations in the $A D A 2$ Gene
}

\author{
Alisa Mo, MD, PhD, Stephanie Donatelli, MD, Leslie A. Benson, MD, Pui Y. Lee, MD, PhD, and \\ Michael J. Rivkin, MD
}

Neurology ${ }^{\circledR} 2021 ; 97: 696-699$. doi:10.1212/WNL.0000000000012271

\author{
Correspondence \\ Dr. Rivkin \\ michael.rivkin@ \\ childrens.harvard.edu
}

An 18-year-old woman with a history of episodic diplopia, oral ulcers, joint pain, rash, and fatigue presented to the emergency department with acute onset of diplopia. At 9 years of age, she had an episode of diplopia, with MRI of the brain showing a small T2-hyperintense, nonenhancing area of restricted diffusion in the right midbrain (Figure, A). An extensive laboratory workup, including hypercoagulability screening, rheumatologic evaluation, infectious studies, and CSF analysis, was notable for mild lymphopenia, neutropenia, and von Willebrand Factor antigen at the upper limit of normal. Echocardiogram did not show structural deficits. She subsequently presented at 11 years of age with a second episode of diplopia. Laboratory results were again notable for lymphopenia and neutropenia. Brain MRI revealed a new left paramedian pontine area of restricted diffusion (Figure, B). Diplopia self-resolved over the course of 1 to 2 months with each event.

The patient next presented to the emergency department at 18 years of age with acute onset of diplopia. Further inquiry for systemic symptoms revealed that she had intermittent oral ulcers since 2 years of age, 1 episode of genital ulceration, intermittent metacarpophalangeal joint pain with morning stiffness, several episodes of rash, and frequent fatigue. Little was known about her birth and family histories as she had been adopted. Examination showed horizontal diplopia and a right internuclear ophthalmoplegia. MRI of the brain showed a new T2-hyperintense, nonenhancing lesion with restricted diffusion in the midbrain involving the right medial longitudinal fasciculus (Figure, C). There was no encephalomalacia found in areas of her prior right midbrain and left pontine lesions (Figure, D and E). Head and neck magnetic resonance angiography were normal. Initial laboratory studies reconfirmed lymphopenia and neutropenia that had been present over the prior 9 years. Inflammatory markers were not elevated. CSF analysis showed elevated neopterin but was otherwise unremarkable, with negative oligoclonal bands and normal immunoglobulin $\mathrm{G}$ index. Antibody tests for aquaporin-4 and myelin oligodendrocyte glycoprotein were negative. She was positive for HLA-B51 antigen and had a negative pathergy test. She was discharged home on empiric glucocorticoids to treat a presumed inflammatory disorder that was initially thought to be neuro-Behçet.

A primary immunodeficiency genetic panel subsequently showed 2 heterozygous mutations in adenosine deaminase 2 ( $A D A 2)$. The first mutation, c.973-2A > G, affected the splice acceptor site, whereas the second mutation, c.695T > C, p.(Met232Thr), was a variant of uncertain significance. The c.695T > C variant was not present in the gnomAD population database and was predicted by PolyPhen, SIFT, and MutationTaster to be pathogenic. This finding supported the diagnosis of deficiency in ADA2 syndrome (DADA2), confirmed by near-absent plasma $\mathrm{ADA} 2$ activity $(0.02 \mathrm{mU} / \mathrm{mL}$; reference range $13.0 \pm 5.1 \mathrm{mU} / \mathrm{mL})$. Other laboratory studies were also notable for low serum immunoglobulin $\mathrm{M}$, decreased switched memory B cells, and elevated interleukin-2 receptor. Given the diagnosis of DADA2, she was started on adalimumab. 


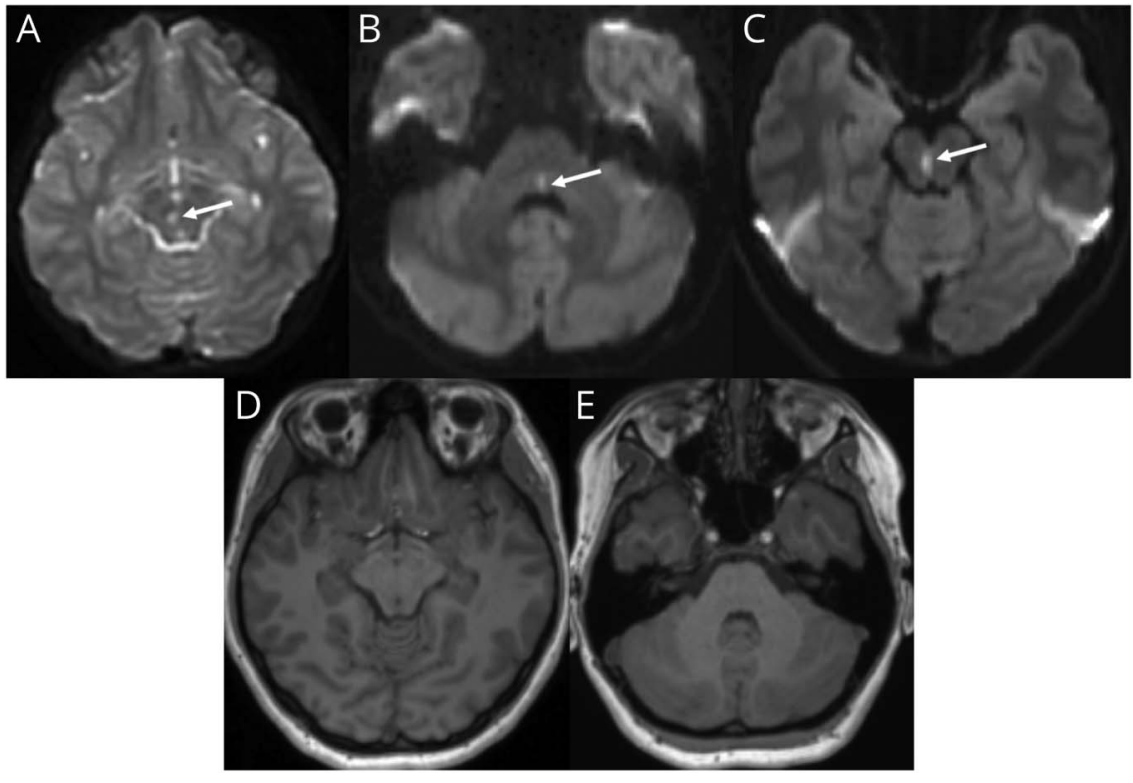

Axial diffusion-weighted MRI brain shows an area of restricted diffusion in the right midbrain at age $9(\mathrm{~A})$, left paramedian pons at age 11 (B), and right midbrain affecting the medial longitudinal fasciculus at age 18 (C). (D, E) Axial T1 MRI brain showing lack of encephalomalacia at age 18 in the areas of restricted diffusion in (A) and (B).

\section{Differential Diagnosis}

The differential diagnosis of ischemic stroke in a child is broad and includes arteriopathies (e.g., focal cerebral arteriopathy, arterial dissection, moyamoya disease), cardiac diseases, infection, hypercoagulable conditions, sickle cell anemia, metabolic conditions, and toxic causes and is presented elsewhere. ${ }^{1}$ Within the category of arteriopathies, several systemic vasculitides can lead to ischemic stroke. These include systemic lupus erythematosus, polyarteritis nodosa, Behçet disease, DADA2, sarcoidosis, and, rarely, Kawasaki disease. Secondary vasculitis from systemic infections and medications can also lead to ischemic stroke.

In addition, nonvascular conditions can mimic stroke in children, show restricted diffusion on brain imaging, and should be considered in the differential. These include demyelinating conditions (e.g., acute disseminated encephalomyelitis, multiple sclerosis, myelin oligodendrocyte glycoprotein-associated disease, neuromyelitis optica spectrum disorder), malignancy (e.g., lymphoma, glioma), infection (e.g., herpes simplex virus), metabolic, and other genetic conditions.

A general diagnostic workup in our institution for a child presenting with ischemic stroke includes brain MRI, head and neck vessel imaging, inflammatory markers, hypercoagulability testing, infectious studies including HIV, autoantibody testing, von Willebrand Factor antigen levels, urine toxicology, telemetry, and echocardiogram. A lumbar puncture should be performed if there is diagnostic uncertainty about a possible demyelinating, infectious, or inflammatory disorder.
The presence of risk factors and specific clinical features on history, examination, and initial laboratory studies guide the direction of further workup. In our patient, the combination of her episodic, discrete brainstem lesions and her systemic symptoms pointed us to the diagnosis of a small-vessel, systemic vasculitis causing ischemic stroke. Of the systemic vasculitides, we particularly considered neuro-Behçet syndrome, which can also present with recurrent aphthous ulcers, genital ulcers, myalgias, arthralgias, fatigue, and brainstem lesions with restricted diffusion. ${ }^{2,3}$ Although Behçet disease occurs more commonly in those with the HLA-B51 allele, present in our patient and likely incidental, HLA-B51 alone possesses low diagnostic utility due to its poor sensitivity and specificity in Behçet. ${ }^{3}$ In addition, DADA2 can mimic polyarteritis nodosa (PAN), which can also present with early-onset strokes and systemic inflammation. Other features of PAN can include fever, weight loss, erythematous nodules, livedo reticularis, renal disease, abdominal pain, and a history of hepatitis B infection. Identifying the laboratory abnormalities in immune and bone marrow function that are characteristic of DADA2 and uncommon in Behçet and PAN can help distinguish among these etiologies. A classic finding in DADA2 is mild immunodeficiency with neutropenia, lymphopenia, low switched memory B cells, and low immunoglobulins. A diagnosis of DADA2 is made by $A D A 2$ sequencing. If genetic testing cannot be sent, $\mathrm{ADA} 2$ activity can be measured by enzyme testing. 4

\section{Clinical Phenotype of DADA2}

First described in 2014, DADA2 is a monogenic systemic vasculitis caused by recessive loss-of-function mutations in $A D A 2$ (previously known as CECR1). ${ }^{4}$ The $A D A 2$ gene 
encodes a secreted dimeric protein that is highly expressed in monocytes, macrophages, and dendritic cells. Although it may function in purine metabolism to break down adenosine, it appears to have additional functions in regulating cell proliferation and differentiation. Deficiency of ADA2 is hypothesized to polarize monocytes/macrophages to the M1 proinflammatory phenotype, which promotes inflammation and vascular breakdown. ${ }^{4}$

Clinical features of DADA2 result from vasculopathy of smalland medium-sized arteries and can affect any organ system. In 1 meta-analysis of 161 patients with DADA2, onset of disease typically occurs in childhood, with $24 \%$ of patients presenting before 1 year of age and $77 \%$ presenting before 10 years. ${ }^{5}$ There is extensive phenotypic heterogeneity. Mucocutaneous findings are most common, seen in $75 \%$ of affected patients, and include livedo reticularis, cutaneous polyarteritis nodosa, and Raynaud phenomenon. Aphthous ulceration is present in $7 \%$ of affected individuals. ${ }^{5}$

Notably, neurologic events are seen in $50 \%$ of patients. ${ }^{5}$ Ischemic stroke has been shown to be the most common neurologic finding (27\%), followed by cranial nerve palsy (14\%), hemorrhagic stroke (12\%), polyneuropathy (9\%), and other neurologic manifestations (16\%). Rarely, case reports have also described spastic diplegia, ataxia, sensorineural hearing loss, mononeuritis multiplex, labyrinthitis, encephalopathy, and cerebral atrophy. ${ }^{5,6}$ Lacunar stroke occurrence in the subcortical gray matter or brainstem is common. ${ }^{5}$

About half of patients with DADA2 have hematologic and immunologic abnormalities of varying types and severity, including mild immunodeficiency, common variable immunodeficiency, pure red cell aplasia, and bone marrow failure. ${ }^{6,7}$ Laboratory studies may demonstrate multilineage cytopenia including lymphopenia, neutropenia, anemia, and thrombocytopenia., 5 The immune profile can show low switched memory B cells and low levels of immunoglobulin $\mathrm{G}$, immunoglobulin $\mathrm{M}$, or immunoglobulin A. Other reported clinical features include intermittent fever, lymphoproliferative disease, hypertension, abdominal pain, portal hypertension, myalgias, and arthralgias. ${ }^{5,6}$ DADA2 should be considered in a child with early-onset stroke and evidence of a systemic vasculopathy.

\section{Treatment and Prognosis}

The first-line treatment of DADA2 is tumor necrosis factor (TNF) inhibition, which has been shown to reduce the risk of strokes. In studies of pediatric and young adult patients with DADA2, treatment with TNF inhibitors was associated with a significant reduction of stroke events. ${ }^{8,9}$ Anti-TNF agents also attenuated inflammatory markers, anemia, hepatomegaly, and liver fibrosis. Our patient was started on adalimumab at $40 \mathrm{mg}$ every 2 weeks, while her glucocorticoids were tapered. Her diplopia gradually resolved after 8 weeks, and glucocorticoids were discontinued.
As there is an increased risk of hemorrhagic stroke in DADA2, aspirin and anticoagulants are typically avoided except when there is a strong indication for their use. ${ }^{5}$ Patients with refractory disease or severe bone marrow failure have been treated with hematopoietic stem cell transplant with success. $^{10}$

DADA2 has a broad phenotypic spectrum. Patients may experience rapidly progressive disease leading to death in childhood, whereas others can remain asymptomatic until adulthood. From a neurologist's diagnostic perspective, it is important to recognize in DADA2 the combination of small-vessel ischemic strokes or hemorrhagic strokes, particularly in a child, together with systemic findings and characteristic laboratory abnormalities. DADA2 may be underdiagnosed due to the phenotypic overlap with other vasculitides and lack of standard screening guidelines for this disorder in children with stroke. However, recurrent lacunar stroke of subcortical gray matter and brainstem in children is infrequently cryptogenic and should raise suspicion for DADA2. Early diagnosis will lead to treatment with a TNF inhibitor that can prevent further stroke and neurologic disability.

\section{Study Funding}

The authors report no targeted funding.

\section{Disclosure}

The authors report no disclosures relevant to the manuscript. Go to Neurology.org/N for full disclosures.

Appendix Authors

\begin{tabular}{lll}
\hline Name & Location & Contribution \\
\hline $\begin{array}{l}\text { Alisa Mo, MD, } \\
\text { PhD }\end{array}$ & $\begin{array}{l}\text { Boston Children's } \\
\text { Hospital, MA }\end{array}$ & $\begin{array}{l}\text { Design and conceptualization of } \\
\text { manuscript, drafting and revision of } \\
\text { manuscript }\end{array}$ \\
\hline $\begin{array}{l}\text { Stephanie } \\
\text { Donatelli, } \\
\text { MD }\end{array}$ & $\begin{array}{l}\text { Boston Children's } \\
\text { Hospital, MA }\end{array}$ & $\begin{array}{l}\text { Design and conceptualization of } \\
\text { manuscript, revision of manuscript for } \\
\text { intellectual content }\end{array}$ \\
\hline $\begin{array}{l}\text { Leslie A. } \\
\text { Benson, MD }\end{array}$ & $\begin{array}{l}\text { Boston Children's } \\
\text { Hospital, MA }\end{array}$ & $\begin{array}{l}\text { Revision of manuscript for intellectual } \\
\text { content }\end{array}$ \\
\hline $\begin{array}{l}\text { Pui Y. Lee, } \\
\text { MD, PhD }\end{array}$ & $\begin{array}{l}\text { Boston Children's } \\
\text { Hospital, MA }\end{array}$ & $\begin{array}{l}\text { Revision of manuscript for intellectual } \\
\text { content }\end{array}$ \\
\hline $\begin{array}{l}\text { Michael J. } \\
\text { Rivkin, MD }\end{array}$ & $\begin{array}{l}\text { Boston Children's } \\
\text { Hospital, MA }\end{array}$ & $\begin{array}{l}\text { Design and conceptualization of } \\
\text { manuscript, revision of manuscript for } \\
\text { intellectual content }\end{array}$ \\
\hline
\end{tabular}

\section{References}

1. Mackay MT, Wiznitzer M, Benedict SL, et al. Arterial ischemic stroke risk factors: the International Pediatric Stroke Study. Ann Neurol. 2011;69(1):130-140.

2. Kakkar C, Kakkar S, Saggar K, Goraya JS, Ahluwalia A, Arora A. Paediatric brainstem: a comprehensive review of pathologies on MR imaging. Insights Imaging. 2016;7(4): 505-522.

3. Kalra S, Silman A, Akman-Demir G, et al. Diagnosis and management of neuroBehçet's disease: international consensus recommendations. J Neurol. 2014;261(9): 1662-1676.

4. Zhou Q, Yang D, Ombrello AK, et al. Early-onset stroke and vasculopathy associated with mutations in ADA2. N Engl J Med. 2014;370(10):911-920. 
5. Meyts I, Aksentijevich I. Deficiency of adenosine deaminase 2 (DADA2): updates on the phenotype, genetics, pathogenesis, and treatment. J Clin Immunol. 2018;38(5): 569-578.

6. Lee PY. Vasculopathy, immunodeficiency, and bone marrow failure: the intriguing syndrome caused by deficiency of adenosine deaminase 2. Front Pediatr. 2018;6:282

7. Lee PY, Kellner ES, Huang Y, et al. Genotype and functional correlates of disease phenotype in deficiency of adenosine deaminase 2 (DADA2). J Allergy Clin Immunol. 2020;145(6):1664-1672.
8. Ombrello AK, Qin J, Hoffmann PM, et al. Treatment strategies for deficiency of adenosine deaminase 2. N Engl J Med. 2019;380(16):1582-1584.

9. Cooray S, Omyinmi E, Hong Y, et al. Anti-tumour necrosis factor treatment for the prevention of ischaemic events in patients with deficiency of adenosine deaminase 2 (DADA2). Rheumatology. Epub 2021 Jan 9.

10. Hashem H, Kumar AR, Müller I, et al. Hematopoietic stem cell transplantation rescues the hematological, immunological, and vascular phenotype in DADA2. Blood. $2017 ; 130(24): 2682-2688$

\section{Subspecialty Alerts by E-mail!}

Customize your online journal experience by signing up for e-mail alerts related to your subspecialty or area of interest. Access this free service by clicking on the "My Alerts" link on the home page. An extensive list of subspecialties, methods, and study design choices will be available for you to choose from-allowing you priority alerts to cutting-edge research in your field!

\section{Online Learning for Everyone}

No matter your career stage, interest, or learning style, the AAN has a wide variety of convenient online CME, self-assessment, and other learning activities to suit your needs. From bite-sized learning opportunities to self-assessment programs, help preparing you for the boards or continuing certification, or on-demand access to popular AAN conferences, the AAN has you covered. Visit AAN.com/Learn today.

\section{Visit the Neurology ${ }^{\circledast}$ Resident \& Fellow Website}

Click on Residents \& Fellows tab at Neurology.org.

Now offering:

- Neurology ${ }^{\circledR}$ Resident \& Fellow Editorial team information

- "Search by subcategory" option

- E-pearl of the Week

- RSS Feeds

- Direct links to Continuum ${ }^{\circledR}$, Career Planning, and AAN Resident \& Fellow pages

- Recently published Resident \& Fellow articles

- Podcast descriptions

- Blogs by Editors and Resident \& Fellow team members

f Find Neurology ${ }^{\circledR}$ Residents \& Fellows Section on Facebook: facebook.com/AANResidentsAndFellows

Follow Neurology ${ }^{\circledR}$ on Twitter: @GreenJournal \#NeurologyRF

(0) Find Neurology ${ }^{\circledR}$ Residents \& Fellows Section on Instagram: @aanbrain \#NeurologyRF 


\section{Neurology}

\section{Child Neurology: Recurrent Brainstem Strokes and Aphthous Ulcers in a Child With Mutations in the $A D A 2$ Gene}

Alisa Mo, Stephanie Donatelli, Leslie A. Benson, et al. Neurology 2021;97;696-699 Published Online before print May 26, 2021

DOI 10.1212/WNL.0000000000012271

This information is current as of May 26, 2021

\section{Updated Information \& Services}

References

Subspecialty Collections

Permissions \& Licensing

Reprints including high resolution figures, can be found at: http://n.neurology.org/content/97/14/696.full

This article cites 9 articles, 1 of which you can access for free at: http://n.neurology.org/content/97/14/696.full\#ref-list-1

This article, along with others on similar topics, appears in the following collection(s):

Childhood stroke

http://n.neurology.org/cgi/collection/childhood_stroke MRI

http://n.neurology.org/cgi/collection/mri

Pediatric stroke; see Cerebrovascular Disease/ Childhood stroke http://n.neurology.org/cgi/collection/pediatric_stroke_see_cerebrovascu lar_disease-childhood_stroke

Vasculitis

http://n.neurology.org/cgi/collection/vasculitis

Information about reproducing this article in parts (figures,tables) or in its entirety can be found online at:

http://www.neurology.org/about/about_the_journal\#permissions

Information about ordering reprints can be found online:

http://n.neurology.org/subscribers/advertise

Neurology ${ }^{\circledR}$ is the official journal of the American Academy of Neurology. Published continuously since 1951, it is now a weekly with 48 issues per year. Copyright () 2021 American Academy of Neurology. All rights reserved. Print ISSN: 0028-3878. Online ISSN: 1526-632X.

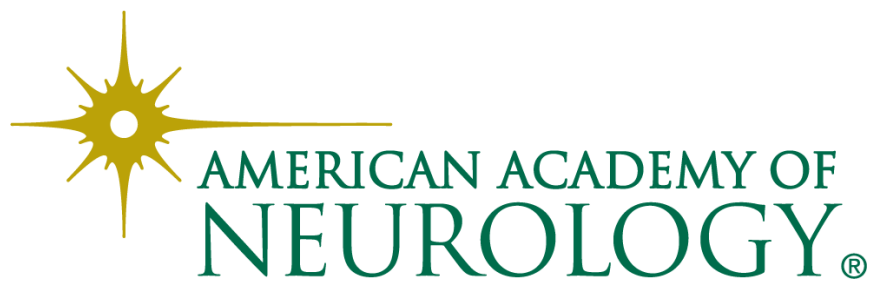

